\title{
Introducción al estudio del Derecho Procesal Constitucional*
}

\author{
La vida, la realidad y el porvenir \\ de las cartas constitucionales de \\ nuestra época, descansan en la \\ justicia constitucional.
}

Mauro Cappelletti

En estas notas se analizará el concepto, origen, importancia, contenido y funciones que cumple el Derecho Procesal Constitucional, custodio máximo del estado de derecho, destacando especialmente la trascendencia que hoy tiene su implementación y reconocimiento en un país que cuente con una democracia efectiva, regulada en lo esencial por una Constitución que contenga las normas básicas que regulen el ejercicio del poder por parte de la autoridad y el pleno reconocimiento de las garantías constitucionales fundamentales, incluyendo en ambos casos su plena y completa protección jurisdiccional, a través del debido proceso.

En este entorno concuerdo con Mauro CAPPELLETTI en cuanto expresa que la Constitución no debe ser concebida como una simple pauta de carácter político, moral o filosófico, sino como una ley verdadera positiva y obligante con carácter supremo y más permanente que la legislación positiva ordinaria. Desde otra perspectiva, pero en el mismo ámbito, GARCÍA DE ENTERRÍA concluye que hoy las constituciones son normas jurídicas efectivas, que prevalecen en el proceso político, en la vida social y económica del país y que sustentan la validez a todo el orden jurídico, y deseo agregar que la Constitución es una norma decisoria litis aplicable por los jueces constitucionales en los procesos sometidos a su competencia.

Sin duda, la globalización que hoy experimenta el mundo, ha impactado los sistemas judiciales, especialmente los constitucionales, generando la necesidad de decidir jurisdiccionalmente los nuevos conflictos que surgen como consecuencia de la aplicación universal e imperativa del principio de la supremacía constitucional, de la integración de los países y de la necesaria protección integral de los derechos de las personas, cualquiera sea el lugar en que se encuentren. La vieja Europa, sabia maestra,

* (N. de. E.). Las presentes notas forman parte de una obra mayor en preparación. Agradecemos desde ya al autor la deferencia con nuestra revista de remitir el presente documento como un adelanto a dicha obra. 
sigue a la vanguardia jurídica, lo que ha permitido institucionalizar la Unión Europea y establecer los mecanismos jurisdiccionales de solución de sus controversias, acontecimiento ejemplificador y determinante para el éxito de sus propósitos.

Nuestra América Latina recién despierta frente a estas tendencias donde sus sistemas jurídicos permanecen herméticos regulando su vida interna, en circunstancias que las relaciones de todo tipo entre los países, son cada día más fuertes y frecuentes. No obstante, en este contexto miramos como excepcional y trascendente la vinculación que en los últimos años se ha consolidado entre los tribunales constitucionales de los distintos países, los que por operar en el ámbito de una nueva dimensión de la jurisdicción, que se rige por principios informadores diferentes a los de los tribunales comunes, presentan áreas de contacto muy afines, lo que ha permitido compartir sus experiencias.

Personalmente, con mi dedicación al estudio del derecho procesal constitucional, observo que su preceptiva opera fluidamente en la justicia constitucional, toda vez que las constituciones contienen disposiciones básicas similares, lo que permite a sus operadores lograr una utilización adecuada de la doctrina comparada y de la jurisprudencia emanada de las sentencias de los tribunales establecidos por los respectivos ordenamientos.

Debe observarse que tanto los conflictos constitucionales entre poderes públicos, como los producidos por violación de las garantías constitucionales de las personas, son en esencia similares en todos los países.

Hoy sin duda, los valores y principios constitucionales ya son un patrimonio jurídico de la humanidad que las constituciones políticas deben necesariamente aprovechar, incorporándolos en sus textos y contemplando, como su natural consecuencia, un sistema jurisdiccional que los proteja.

Como viejo juez constitucional, con misión cumplida y muy conocedor de los tribunales constitucionales de muchos países, puedo afirmar que frente a un caso a decidir, las fuentes doctrinarias y jurisprudenciales extranjeras son normalmente consultadas, lo que confirma, desde mi punto de vista, la universalidad de los principios que informan la justicia constitucional.

En esta introducción resulta también necesario destacar cuáles han sido las principales razones que han conducido al éxito de esta nueva disciplina y que podrían precisarse en tres ámbitos. El primero se genera con la restauración de la democracia y el estado de derecho en los países de Europa y en los de otros continentes que han logrado eliminar los regímenes de facto y reemplazarlos por un sistema de derecho. Ello ha significado que han debido incorporar mecanismos de protección jurisdiccional de los dos grandes valores que sustentan el contenido de una constitución política, como lo son el poder del Estado y la distribución de su ejercicio entre las diversas autoridades y las garantías constitucionales fundamentales de sus habitantes. Como bien afirma Néstor Pedro SAGÜES "es el estado de derecho, democrático y constitucional, el hábitat natural de esta rama del mundo jurídico”2.

Como segunda razón puede invocarse el establecimiento de tribunales o salas constitucionales en la mayor parte de los países que cuentan con un estado de derecho en los que aplica directamente la Constitución para resolver los conflictos de su competencia, lo que necesariamente conduce a normar

\footnotetext{
${ }^{2}$ Libro sobre Derecho Procesal Constitucional “Logros y Obstáculos”, página 36.
} 
procedimientos constitucionales y a consagrar al debido proceso como el medio de solución de tales conflictos sometidos a su imperio.

Finalmente, como tercera razón resulta esencial reiterar que hoy la Constitución es una norma decisoria litis aplicable directamente por los jueces al decidir los conflictos constitucionales. Esta competencia la tienen todos los tribunales de la nación cuando el país cuenta con un sistema de control difuso, y si es concentrado, los que señale la Constitución y la ley.

En este entorno deseo destacar que Héctor Fix ZAMUDIO en su presentación a la primera edición del Derecho Procesal Constitucional Tomo I, coordinado por Eduardo Ferrer MAC-GREGOR, explica por qué surgió esta nueva rama del Derecho al preguntarse “¿Qué determina la autonomía plena de una disciplina jurídica?” Esta interrogante cobra relevancia en el caso del Derecho Procesal Constitucional.

Si bien en la materia que estamos analizando, compartiendo los principios y estructuras de dos ramas tradicionales y ampliamente consolidadas, como lo son el Derecho Procesal y El Constitucional, existen en la actualidad parámetros o realidades objetivas para sustentar su independencia bajo tres ópticas distintas que son, como lo precisa Néstor Pedro Sagües, la legislación, la magistratura especializada y la doctrina que se han coludido para integrar este nuevo derecho, ello coincide con las razones fundantes del acelerado desarrollo de esta nueva disciplina.

a. Legislación. Los ordenamientos constitucionales contemporáneos han incorporado paulatinamente a sus legislaciones diversos instrumentos jurisdiccionales con la finalidad de hacer respetar la Constitución y evitar el quebranto de la norma superior (amparo, hábeas corpus, hábeas data, acción abstracta de inconstitucionalidad de las leyes, controversias constitucionales -conflicto de atribuciones- cuestión de inconstitucionalidad y otros), lo que se refleja y desarrolla en las leyes procesales específicas que los regulan. Incluso, en algunos países ya existen códigos procesales constitucionales que de manera general se refieren a varios procedimientos constitucionales, como ocurre en Argentina (Provincia de Entre Ríos y de Tucumán), Guatemala, Costa Rica y Perú.

b. Magistratura especializada. También de manera progresiva se ha establecido una magistratura especializada para la resolución de los conflictos constitucionales, logrando residualmente precisar la función interpretativa de la normativa constitucional.

En América hoy existen tribunales que tienen competencia para realizar dicha función de manera exclusiva siguiendo el modelo europeo de control constitucional, denominados cortes o tribunales constitucionales (Bolivia, Guatemala, Chile, Colombia, Ecuador y Perú). En otros casos se han creado salas constitucionales dependientes de las propias cortes supremas (El Salvador, Costa Rica, Nicaragua, Paraguay y Venezuela). Incluso en algunos países donde no existen estos tribunales o salas constitucionales, el máximo órgano jurisdiccional ordinario realiza funciones de control constitucional, aunque no de manera exclusiva como sucede en Argentina, Brasil y México.

c. Doctrina. A partir del nacimiento de los tribunales constitucionales europeos en la segunda década del siglo XX, se inició el estudio sistemático de los procesos constitucionales y de la magistratura especializada para resolverlos. Especialmente en las últimas tres décadas, los constitucionalistas principalmente, y ahora también los procesalistas, han enfocado sus esfuerzos en establecer la denominación, el contenido y los límites del Derecho Procesal Constitucional como nueva disciplina 
jurídica. Existen avances importantes al existir obras con esta denominación en varios países (Alemania, Argentina, Brasil, Costa Rica, Colombia, España, Nicaragua y Perú), al margen de las múltiples monografías sobre procesos constitucionales específicos o en general, sobre justicia, jurisdicción, control o defensa constitucional.

Podemos agregar que asimismo, han proliferado los cursos y seminarios con la denominación de derecho procesal constitucional (especialmente en Argentina), incorporándose, en algunos países, en los programas de las escuelas o facultades de derecho -Universidad Panamericana de la Ciudad de México y en el postgrado de la maestría de Derecho Constitucional y Amparo de la Universidad Autónoma de Tlaxcala. También existen institutos de investigación, como el Centro Interdisciplinario de Derecho Procesal Constitucional de la Facultad de Derecho y Ciencias Sociales del Rosario, de la Universidad Católica de Argentina.

Hoy existe una clara trilogía donde se entrelazan los conceptos de constitución, jurisdicción constitucional y debido proceso constitucional.

El Derecho Constitucional clásico se ve así reforzado con los mecanismos eficientes de protección que le proporciona el nuevo y vigoroso Derecho Procesal Constitucional.

En efecto, las constituciones políticas modernas en sus textos consagran los principios, valores y bases del sistema jurídico normativo, el que, para ser eficaz, debe necesariamente contar con un mecanismo que resuelva jurisdiccionalmente los conflictos producidos por su quebrantamiento formal o sustancial. Recordemos que la doctrina clásica eliminaba toda posibilidad de control jurisdiccional de las leyes.

Hoy observamos cómo el mundo civilizado en sus cartas básicas garantiza los derechos de las personas, regula sus relaciones con el Estado, distribuye el poder entre los diversos organismos públicos creados por la Constitución e instaura un sistema jurisdiccional integral que protege y garantiza la eficacia real de sus disposiciones y valores.

En este contexto, resulta evidente que la jurisdicción juega un nuevo rol trascendental al posicionarse como el medio idóneo destinado a resguardar, a través del debido proceso, el estado de derecho y la supremacía constitucional, principios fundamentales para regir los destinos de cada país y los de sus habitantes y para protegerlos frente a cualquier tipo de quebrantamiento normativo o abuso de poder.

Es por ello que el profesor Louis Favoreu, en su trabajo "Justicia y Jueces Constitucionales", afirma que el desarrollo de la justicia constitucional es ciertamente el acontecimiento más destacado del Derecho Público del siglo XX, en el viejo mundo y quizás en el mundo entero, y concluye que hoy no se concibe un sistema constitucional que no reserve un lugar a esta institución. Esto explica que en Europa, todas las nuevas constituciones han previsto, además de una Corte Suprema o de un Tribunal de Casación, la existencia de un Tribunal Constitucional, al igual como lo han hecho algunos países latinoamericanos.

Esto es algo necesario de lograr en todo ordenamiento jurídico que se respete.

En esta perspectiva, la constitución así estructurada definitivamente se plantea como una norma decisoria litis de aplicación directa por el juez, en la solución de todo conflicto constitucional sometido a su imperio. 
Puede decirse que hoy presenciamos una nueva legitimidad, la legitimidad constitucional y que existe coincidencia académica, en que toda constitución impone la necesidad de contar con un órgano jurisdiccional que garantice el cumplimiento y la plena observancia de sus normas, valores y principios y el acceso a un debido proceso que le permita ser efectiva.

En este entorno, el debido proceso se perfila como la culminación de la protección jurisdiccional de la Constitución, toda vez que si consideramos solamente la jurisdicción constitucional en abstracto y no al instrumento destinado a hacerla efectiva en el caso concreto, estaríamos frente a un sistema imposible, incompleto e inoperante de justicia constitucional.

Concuerdo con la doctrina italiana que jurisdicción y proceso son conceptos indisolublemente unidos y que no pueden subsistir el uno sin el otro.

La jurisdicción sin proceso es inviable y el proceso sin jurisdicción no es un proceso jurisdiccional y, por lo tanto, lo inhibe para decidir un conflicto de intereses de relevancia constitucional, con efecto de cosa juzgada.

Siendo así la protección jurisdiccional de las disposiciones constitucionales por medio del debido proceso, es el mecanismo que le permite recuperar su eficacia real, en caso de producirse un acto de cualquier sujeto que las quebrante. La sentencia que lo decida es el medio natural que reivindicará la plena vigencia de la norma constitucional vulnerada con la presencia del conflicto y le restituirá su plena vigencia real.

Es aquí donde emerge la figura de su guardián, el Tribunal Constitucional, magistral creación de KELSEN destinada a garantizar la eficacia de la supremacía constitucional a través del debido proceso.

Muy bien ha dicho CALAMANDREI, que todas las declaraciones constitucionales son fútiles, si no existen medios jurídicos procesales que aseguren su eficacia real.

Recordemos que a partir de la Revolución Francesa y de la consagración del principio de la separación de los poderes públicos, al sistema judicial le estaba vedado inmiscuirse en las atribuciones legislativas y administrativas por lo que, como ya se dijo, carecía de jurisdicción para resolver conflictos constitucionales.

Sin embargo, el mundo ha presenciado las discrepancias entre los poderes públicos y la necesidad de resolverlas por medios racionales y pacíficos. Esta confrontación entre la exigencia de instaurar un control jurisdiccional de la Constitución y conservar en su esencia el principio de separación de poderes, fue precisamente lo que motivó, a partir de KELSEN, la creación de tribunales constitucionales con la atribución jurisdiccional específica de velar por la constitucionalidad de las leyes, la que no podría atribuirse al orden judicial tradicional, cuya misión, precisamente, es la de aplicar la ley sin que le fuere lícito cuestionarla.

Luego este control de constitucionalidad se extenderá a los actos administrativos y según algunos, debiera también alcanzar la posibilidad de invalidar sentencias de los tribunales comunes, por vicios de inconstitucionalidad.

De lo expuesto surge la diferencia esencial entre la jurisdicción común y su ampliación para incluir la solución de conflictos constitucionales. La primera aplica la ley como norma decisoria litis y la segunda la Constitución, que recoge además elementos universales. 
Esta área apunta directamente al centro del tema de nuestra convocatoria, ya que en la práctica las constituciones exigen y consagran garantizar por la vía jurisdiccional, el principio de la supremacía constitucional, postulado ya universalmente aceptado y reconocido por la mayor parte de las cartas políticas del mundo. Su protección, a través de la jurisdicción, constituye un elemento esencial para garantizar su eficacia.

También resulta trascendente tener en cuenta que el ejercicio de la jurisdicción constitucional permite lograr la interpretación y adaptación de los textos y valores establecidos en la Constitución, expresados a través de sentencias necesariamente fundadas de los tribunales constitucionales.

Sin embargo, reitero una vez más que como es fácil comprender, no basta con proclamar que las normas contenidas en la Constitución son las de mayor jerarquía dentro del ordenamiento jurídico de un Estado, para que éstas sean respetadas por los poderes constituidos y obren así como límite de sus atribuciones y eficaz salvaguardia de los derechos del hombre. Siempre subsistirá la posibilidad de que los órganos que ejercen los poderes sobrepasen las disposiciones de la Carta Fundamental y, extralimitándose en el ejercicio de sus atribuciones, pongan en peligro la institucionalidad misma de la República. La sola declaración de la supremacía constitucional resulta, pues, insuficiente.

Al hablar de este tema debe incluirse, necesariamente, la protección de las disposiciones escritas en la Constitución, como también y especialmente los valores y principios fundamentales que contiene, todos los que, por la vía de la decisión jurisdiccional, deben cobrar plena vigencia.

También debe destacarse que este control de constitucionalidad implica la configuración de un mecanismo de defensa jurisdiccional de un orden constitucional concreto incorporado en una Constitución, y que se caracteriza por ser asumido por sujetos ajenos al proceso de producción normativa y por recaer, salvo excepciones, sobre normas perfectas y plenamente vigentes. Se plantea formalmente como la garantía de la primacía de la Constitución sobre las demás disposiciones del ordenamiento jurídico positivo.

La experiencia interna es válida para todos, en cuanto aquellas que articulan la jurisdicción constitucional deben interpretarse para que potencien al máximo su defensa y cumplimiento. En este orden de ideas, la jurisdicción constitucional tiene un significado esencial para el perfeccionamiento y la vigencia del estado constitucional de derecho, la división y equilibrio de las ramas del poder público, la distinción entre poder constituyente y poderes constituidos, la división vertical del poder del Estado y el respeto de los derechos fundamentales.

Debe tenerse en cuenta, además, que esta ampliación de la jurisdicción permite a los tribunales constitucionales desempeñar una función esencial de adaptación de la constitución y de los textos que la complementan a la realidad nacional, en los casos en que su rigidez provoque problemas en la aplicación de sus normas o una alteración de las garantías en su esencia.

Para cumplir su alta misión deben contar con jurisdicción suficiente para resolver los conflictos propiamente contenciosos y para intervenir, a través de la jurisdicción de certeza, en el control preventivo de las leyes. Con ello, al ejercer su jurisdicción en uno y otro caso, garantizan plenamente el principio de supremacía constitucional, logrando así dar eficacia real a los derechos contemplados en la Constitución Política. 
También es un vaso comunicante el que se refiere a los límites funcionales de esta jurisdicción especializada, pues aunque el Tribunal Constitucional, en su calidad de intérprete supremo de la Constitución, determine de modo vinculante el sentido de los preceptos constitucionales, a él también le corresponde delimitar sus propias funciones, acotando su jurisdicción del ámbito de actuación perteneciente a los tradicionales poderes del Estado.

Como afirman en España TOMÁS y VALIENTE, dentro del sistema constitucional, "Nadie puede decirle al tribunal cuáles son sus límites, lo cual no significa que no los tenga, sino que éstos son los que la Constitución dice que son, en unos términos cuyo sentido establece el propio tribunal como intérprete supremo".

La suma de estos factores es la que da eficacia al principio del mérito del proceso, que enmarca la competencia del Tribunal Constitucional en la solución del caso concreto.

Incorporando un nuevo elemento en esta introducción, resulta de especial interés tener presente que Domingo GARCÍA BELAUNDÉ y Eloy ESPINOSA-SALDAÑA realizaron una encuesta sobre el Derecho Procesal Constitucional donde participaron cuarenta académicos especialistas seleccionados de Europa y América Latina, con sus respuestas al cuestionario consolidan plenamente la definición del Derecho Procesal Constitucional, el que ocupa en el mundo jurídico y su avance en los países que participaron y el interés por su enseñanza en la facultades de Derecho, con lo cual queda confirmada la existencia, importancia y aplicación de esta rama del Derecho en los sistemas constitucionales contemporáneos.

Las constituciones políticas, al regular las relaciones del Estado y sus habitantes, son las que con su aplicación generan conflictos constitucionales especialmente cuando los poderes públicos extralimitan sus atribuciones y en los casos en que el Estado o los particulares violenten las garantías constitucionales que su texto garantiza a los habitantes del país. Éllo llevó a incorporar a sus textos instrumentos jurisdiccionales tendientes a proteger efectivamente la Constitución mediante el ejercicio de las acciones de inconstitucionalidad y de amparo que trascienden a la tradicional normativa procesal establecida en sus legislaciones.

Esta reflexión se ve confirmada en el libro "Derecho Procesal Constitucional" de Osvaldo A. GOZAÍNI en cuanto expresa, en líneas generales, que el programa de reconocimiento de un Derecho Procesal Constitucional queda de manifiesto con la consagración de normas fundamentales que declaran principios y garantías vinculadas con el proceso judicial.

La incorporación de mecanismos que aseguran el control eficiente de la constitucionalidad de las leyes y la implementación de una justicia especial para proteger la Constitución, mayoritariamente, por tribunales constitucionales, agrega un motivo más para la autonomía afirmada, agregando que el Derecho Procesal Constitucional se ha perfilado en este siglo como una disciplina independiente del Derecho Constitucional y del Procesal, pues en la fusión de ambos pareciera estar el sustento de la materia.

Por su parte, desde la vieja Europa, Luigi FERRAJOLI ha calificado su establecimiento como la conquista más importante del derecho contemporáneo para el logro de la protección jurisdiccional de la dignidad de las personas y de los derechos fundamentales frente a la ley, los que no podrían sobrevivir si carecen de una tutela eficaz a través del proceso, planteamiento que coincide con la posición 
de Luis FAVOREU, quien expresa que "personalmente, estimo que es correcta la denominación de Derecho Procesal Constitucional, puesto que su contenido se refiere a la competencia jurisdiccional constitucional y al proceso que debe seguirse para decidir sobre las garantías y no a preceptos constitucionales que se encuadran en el marco de la Constitución en forma estática”.

Debe destacarse que la nueva dimensión de esta disciplina se encuentra estrechamente vinculada a la consagración del sistema del control concentrado de constitucionalidad, toda vez que los países que han elegido el modelo del control difuso no requieren más normas que las procesales que ya tienen. Siendo así, en este último caso, el Derecho Procesal interno, con las adecuaciones necesarias, resulta suficiente para obtener un control jurisdiccional de constitucionalidad, pero hoy los países mayoritariamente se han inclinado por contemplar el concentrado.

Recordemos nuevamente que esta confrontación entre la necesidad de instaurar un control jurisdiccional de la Constitución y conservar el principio de la separación de poderes fue precisamente lo que llevó a la creación de tribunales constitucionales en Europa continental, con la atribución jurisdiccional particular y específica de velar por la constitucionalidad de las leyes, la que no podría atribuirse al orden judicial tradicional, cuya misión, precisamente, es la de aplicar la ley sin que le sea lícito cuestionarla.

Surgen así las acciones de inaplicabilidad de la ley y de inconstitucionalidad y amparo.

La nueva democracia surgida luego de la Segunda Guerra Mundial llevó a la creación de una magistratura especializada para decidir los conflictos constitucionales, lo que hace que la doctrina en el marco de este nuevo derecho asuma la tarea de explicar y normar esta nueva institucionalidad e incorporarla a los planes de estudio de las escuelas de Derecho.

Hoy su ámbito excede a la soberanía de los países y surge en el área que cubre lo que Héctor Fix denomina la justicia o jurisdicción trasnacional, cuyo ejemplo más relevante y reciente es el estatuto jurídico de la comunidad europea.

Volviendo al tema central, bien plantea Eduardo FERRER que ha llegado la hora en que los procesalistas y constitucionalistas unan sus conocimientos con el fin de lograr la plena convalidación del Derecho Procesal Constitucional como disciplina autónoma.

Entre sus precursores debe siempre recordarse al Chief Justice Marshall de la Corte Suprema de los Estados Unidos, en su sentencia del año 1803 “Marbury vs Madison”, ya que debieron pasar muchos ańos y una Segunda Guerra Mundial para que Hans Kelsen diera forma a un nuevo tribunal que incorpora a la Constitución Política de Austria de 1920. Como comenta Héctor Fix, no obstante que Kelsen se dedicó a la teoría general del derecho y a la filosofía en sus estudios sobre organismos e instrumentos de decisión de controversia de carácter constitucional, sentaba las bases de esta nueva disciplina que abrió la conocida polémica con el jurista aleman Carl Schmith acerca de la naturaleza del órgano de la defensa de la Constitución. Por eso, Niceto Alcalá Zamora destaca a Kelsen como el primer expositor de esta disciplina.

Como nos recuerda Eduardo FERRER Mac-gregor en su libro "Forjadores del Derecho Procesal Constitucional", esta denominación fue empleada a mediados del siglo pasado, por Niceto ALCALÁ ZAMORA y CASTILLO en sus clásicas obras Ensayos de Derecho Procesal Civil, Penal y 
Constitucional (1944) y Proceso, autocomposición y autodefensa (1947). Sin embargo, dicha expresión no alcanzó una consolidación suficiente sino hasta tiempos relativamente recientes para sistematizar las instituciones y principios jurídico-procesales relacionados con las garantías de la Constitución.

Puede afirmarse que el estudio sistemático de la disciplina según la tesis de Alcalá-Zamora, se inicia con el establecimiento de los primeros tribunales constitucionales europeos debido al pensamiento del ilustre jurista Hans Kelsen, que en el año 1928 publica su ensayo denominado La garantie jurisdictionnelle de la Constitution, ocho años después de la introducción de la Alta Corte constitucional de Austria (1920), teniendo dicho estudio un impacto importante en la doctrina europea.

Si bien Kelsen no fue un cultivador del procesalismo científico, se le atribuye la paternidad de la disciplina no sólo por haber sido el promotor para el establecimiento de la Corte Constitucional en la Constitución austriaca, con lo cual se le considera fundador del modelo de control concentrado de constitucionalidad, sino también por haber establecido los lineamientos, principios e instituciones del Derecho Procesal Constitucional en sus aspectos generales, que con anterioridad no se habían estudiado de manera sistemática. Después de este acontecimiento, la polémica surgida entre Kelsen y Carl Schmitt, acerca del órgano del Estado que debería realizar la función de protector o defensor de la Constitución, agudiza el interés científico por la materia y empiezan a multiplicarse los estudios doctrinales especializados.

No obstante que, en gran medida, el estudio sistemático de la disciplina parte del pensamiento de Kelsen, ya en los albores del siglo XIX se había instituido la revisión judicial norteamericana, que con el célebre caso "Marbury vs. Madison", decidido por la Corte Suprema de Justicia de los Estados Unidos y redactado por su Presidente John Marshall en el año 1803, constituye el paradigma de los sistemas de justicia constitucional y, específicamente, del modelo difuso de control de la constitucionalidad.

Se establece así por primera vez un concepto del Derecho Procesal Constitucional como disciplina que se ocupa del estudio de los instrumentos normativos de la Constitución y del pleno amparo de las garantías fundamentales que otorga a los habitantes del país.

Con ello se remueven los obstáculos para el cumplimiento de las normas fundamentales cuando han sido violadas, desconocidas o exista incertidumbre acerca de su alcance o su contenido. 